\title{
Enhancing Anticancer Effect of Gefitinib across the Blood-Brain Barrier Model Using Liposomes Modified with One $\alpha$-Helical Cell-Penetrating Peptide or Glutathione and Tween 80
}

\author{
Kuan-Hung Lin ${ }^{1}$, Shu-Ting Hong ${ }^{1}$, Hsiang-Tsui Wang ${ }^{1}$, Yu-Li Lo ${ }^{1,2, *}$, Anya Maan-Yuh Lin ${ }^{1,2,3, *}$ \\ and James Chih-Hsin Yang ${ }^{4}$ \\ 1 Institute of Pharmacology, National Yang-Ming University, Taipei 112, Taiwan; \\ kuanhunglin@outlook.com (K.-H.L.); cat820819@gmail.com (S.-T.H.); hsiangtsuiwang@gmail.com (H.-T.W.) \\ 2 Faculty of Pharmacy, National Yang-Ming University, Taipei 112, Taiwan \\ 3 Department of Medical Research, Taipei Veterans General Hospital, Taipei 112, Taiwan \\ 4 Institute of Oncology, National Taiwan University, Taipei 106, Taiwan; chihyang@ntu.edu.tw \\ * Correspondence: yulilo@ym.edu.tw (Y.-L.L.); myalin@ym.edu.tw (A.M.-Y.L.); \\ Tel.: +886-228-267-000 (ext. 7095) (Y.-L.L.); +886-228-712-121 (ext. 2688) (A.M.-Y.L.)
}

Academic Editor: Bing Yan

Received: 22 October 2016; Accepted: 22 November 2016; Published: 29 November 2016

\begin{abstract}
Epidermal growth factor receptor (EGFR) tyrosine kinase inhibitors (TKI), such as gefitinib, have been demonstrated to effectively treat the patients of extracranial non-small cell lung cancer (NSCLC). However, these patients often develop brain metastasis (BM) during their disease course. The major obstacle to treat $\mathrm{BM}$ is the limited penetration of anticancer drugs across the blood-brain barrier (BBB). In the present study, we utilized gefitinib-loaded liposomes with different modifications to improve gefitinib delivery across the in vitro BBB model of bEnd. 3 cells. Gefitinib was encapsulated in small unilamellar liposomes modified with glutathione (GSH) and Tween 80 (SUV-G+T; one ligand plus one surfactant) or RF (SUV-RF; one $\alpha$-helical cell-penetrating peptide). GSH, Tween 80 , and RF were tested by the sulforhodamine B (SRB) assay to find their non-cytotoxic concentrations on bEnd. 3 cells. The enhancement on gefitinib across the BBB was evaluated by cytotoxicity assay on human lung adenocarcinoma PC9 cells under the bEnd.3 cells grown on the transwell inserts. Our findings showed that gefitinib incorporated in SUV-G+T or SUV-RF across the bEnd.3 cells significantly reduced the viability of PC9 cells more than that of free gefitinib. Furthermore, SUV-RF showed no cytotoxicity on bEnd.3 cells and did not affect the transendothelial electrical resistance (TEER) and transendothelial permeability of sodium fluorescein across the BBB model. Moreover, flow cytometry and confocal laser scanning microscopy were employed to evaluate the endocytosis pathways of SUV-RF. The results indicated that the uptake into bEnd. 3 cells was mainly through adsorptive-mediated mechanism via electrostatic interaction and partially through clathrin-mediated endocytosis. In conclusion, cell penetrating peptide-conjugated SUV-RF shed light on improving drug transport across the BBB via modulating the transcytosis pathway(s).
\end{abstract}

Keywords: gefitinib; blood-brain barrier (BBB); liposomes; peptides; lung cancer

\section{Introduction}

Non-small cell lung cancer (NSCLC) is one of the most common cancer types in the world. Current epidermal growth factor receptor (EGFR) tyrosine kinase inhibitors (TKIs) treatment, including gefitinib and afatinib, are highly effective to extracranial lung cancer patients with specific EGFR mutations [1]. Despite this, the major cause of death from lung cancer is due to metastases that are 
resistant to therapy. About $30 \%$ to $40 \%$ of patients with NSCLC have brain metastasis (BM) during the course of their disease [2]. The major hurdle to treat $\mathrm{BM}$ is the limited penetration of anticancer drugs across the blood-brain barrier (BBB). Clinical studies have reported that the cerebrospinal fluid-to-plasma ratio of gefitinib in patients with $\mathrm{BM}$ is only $0.3 \%-1.3 \%$ [3].

The BBB is a dynamic barrier protecting the brain against invading organisms and potential neurotoxins [4]. Specific tight junction features of the BBB allow low transport of antineoplastic agents to the brain [5]. Membrane pump transporters such as P-glycoprotein (P-gp), a protein associated with multidrug resistance (MDR), are one of the various mechanisms responsible for hampering drugs across the BBB. A new strategy to augment the permeation of anticancer drugs across the BBB for possible treatment of BM of NSCLC is thus in urgent need.

Gefitinib (trade name Iressa), an EGFR-TKI of first-generation, is the first line treatment for metastatic NSCLC with EGFR mutations (exon 19 deletion or exon 21 L858R mutation) [6]. Gefitinib reversibly binds to ATP binding site of tyrosine kinase and inhibits autophosphorylation of EGFR, thus blocking the downstream signaling of mitogen-activated protein kinase (MAPK) pathway and PI3K in cancer cells [7]. Gefitinib was initially effective for EGFR mutated brain metastases if the dose was increased to $1250 \mathrm{mg}$ /day to provide a cerebrospinal fluid (CSF) concentration of in vitro $\mathrm{IC}_{50}$ [8]. However, clinical application for such high doses of gefitinib was hampered due to the side-effects in GI of diarrhea and skin rash [9]. Moreover, because of gefitinib's low solubility in water and many solvents, the mixture of Cremophor EL, ethanol, and 5\% dextrose is the common cosolvent for administration of gefitinib in liquid formulation. These vehicles can easily lead to a severe allergic reaction and possibly extract lots of plasticizer from polyvinyl chloride (PVC) plastic pipes and infusion bags [10]. Thus, the development of well-designed nanoparticles with multiple functions of modulating the blood-brain barrier, enhancing penetration into the cancer focus, and sustaining release of gefitinib at the tumor sites may provide a potential delivery platform for further improving BM therapy.

In the present study, liposomal delivery systems were attempted to enhance gefitinib penetration across the BBB. The in vitro BBB model was established by growing a monolayer of bEnd.3 cells on transwell inserts. The integrity of BBB was evaluated by measuring transendothelial electrical resistance (TEER) and transendothelial permeability.

Liposomes are composed of one or more lamellae of amphiphilic lipids, enclosing an internal aqueous compartment. Usually, the liposomal lipid bilayer consists of biocompatible and biodegradable lipids, present in biological membranes. One of the most recently applied strategies for drug delivery across the BBB endothelium using functionalized liposomes is based on the transcytosis mechanism using specific receptors on the luminal surface of cells [11]. Thus, our first approach is to use small unilamellar liposomes modified with glutathione (GSH) and Tween 80 (SUV-G+T; one ligand plus one surfactant).

Glutathione (GSH) receptors in the brain were largely localized in the white matter, more specifically in the neuroglial cells. GSH, an endogenous tripeptide, possesses a central nervous system (CNS) concentration up to $3 \mathrm{mM}$ [12]. It has antioxidant-like characteristics and is readily transported across the BBB [13]. Recent reports have demonstrated that GSH can be used as a targeting ligand linked to PEGylated nanoparticles to improve delivery of therapeutics to CNS [14,15]. Among different approaches, the most advanced is 2B3-101, which is a liposomal doxorubicin formulation coated with GSH and PEG. This product has completed a Phase I/IIa clinical trial for multiple brain cancer indications, including glioma and brain metastases of breast cancer $[14,15]$. 
Polymeric nanoparticles modified with surfactants, such as polysorbates, have been demonstrated to help the particles permeate across the BBB [16] and improve brain targeting potential for nanoparticles [17]. Modification of nanoparticles with polysorbate 80 (Tween 80 ) has been reported to cross the BBB by enhancing the plasma adsorption of apolipoproteins, such as apolipoprotein $\mathrm{E}$ (ApoE) or B (ApoB), on the nanoparticle surface and thus enabling them to interact with the low density lipoproteins (LDL) receptor [18]. Such coating may enhance the nanoparticles internalization via receptor mediated endocytosis by brain endothelial cells $[18,19]$. In addition, since polysorbate 80 is also a P-gp modulator, it has been reported that nanoparticle coated with polysorbate 80 may escape the efflux by the P-gp transporter, and thus improving brain capillary endothelial cell uptake of nanoparticles $[19,20]$. In this study, liposomes are prepared with surface modification by GSH and/or Tween 80 to evaluate their BBB penetration and cytotoxicity on human lung adenocarcinoma PC-9 cells.

Furthermore, our second approach is to use liposomes conjugated with $\mathrm{RF}$, one cell-penetrating peptide (CPP). Surface modulation of nanoparticles with CPPs assisted in endosomal escape and expedited their cellular internalization [21]. CPPs have multiple choice in sequence design [22]. A traditional CPP, the trans-activator of transcription (TAT) of HIV-1, has been extensively conjugated on the surface of drug-loaded nanoparticles to increase the transport efficiency across the BBB to the CNS [23]. However, drawbacks of TAT include non-human origin, immunogenicity, and low delivery efficiency [24]. Recent studies have explored a new CPP called RF from screening of the 16 amino acid peptide library [25-28]. The RF peptide has a $\alpha$-helical structure with a high normal cell compatibility, similar cell penetrating and cancer cell death activities compared with those of TAT $[25,27]$. Additionally, RF showed a better cell selectivity than that of TAT. It showed lower uptake into 3T3-L1 cells, but higher uptake into human alveolar epithelial adenocarcinoma A549 cells and human cervical cancer HeLa cells [25]. This peptide was internalized via endocytosis, then surrounded inside endosomes or lysosomes, escaped from endosome, and consequently distributed around the nucleus [25]. Thus, RF possesses the potential to be conjugated into a delivery system with the advantages of high efficiency, low toxicity, and cell selectivity $[25,28]$. In this study, TAT was also evaluated for comparison. Based on the above understanding, we thus aim to utilize gefitinib-encapsulated PEGylated liposomes, which were surface modified with GSH and/or polysorbate 80 or conjugated to RF for enhancing gefitinib across the bEnd 3 cells to exhibit their cytotoxicity on PC9.

\section{Results}

\subsection{Determination of Encapsulation Efficiency (EE)\%, Particle Size, and $\zeta$ Potential of PEGylated Liposomal Gefitinib}

Characteristics of PEGylated liposomes modified with GSH, Tween 80, GSH plus Tween 80, and RF were summarized in Table 1. A schematic graph displaying the formation of PEGylated liposomes conjugated with RF peptide is shown in Figure 1A. These liposomal preparations with or without modification were well-dispersed nanoparticles with sizes changed from $85.8 \pm 3.7 \mathrm{~nm}$ for SUV-T (SUV-Tween 80) to $147.1 \pm 3.9 \mathrm{~nm}$ for SUV-RF (Figure 1B,C; Table 1), with a polydispersity index about 0.1 (Table 1). The mean zeta potential of liposomes was ranged from $-3.82 \pm 0.85$ to $-1.70 \pm 0.16 \mathrm{mV}(n=3$; Table 1$)$. The morphology of these liposomal dispersions was observed by transmission electron microscope (TEM). As demonstrated in Figure 1D, this population of liposomes SUV-RF displayed a diameter around $100 \mathrm{~nm}$. These nanoparticles were close to spherical in shape (Figure 1D). Encapsulation efficiency (EE)\% of these PEGylated liposomes was $86.70 \% \pm 2.75 \%$. 
Table 1. Characterization of gefitinib-loaded liposomes modified with glutathione (GSH), Tween 80 , or RF ${ }^{\mathbf{a}}$.

\begin{tabular}{|c|c|c|c|c|}
\hline Formulation & Description & $\begin{array}{l}\text { Particle Size } \\
\quad(\mathrm{nm})\end{array}$ & PDI $^{b}$ & $\begin{array}{l}\zeta \text { Potential } \\
\quad(\mathrm{mV})\end{array}$ \\
\hline SUV-Mal & $\begin{array}{l}\text { Small unilamellar vesicles of DSPC, cholesterol, } \\
\text { and DSPE-PEG2000-maleimide }\end{array}$ & $95.5 \pm 2.2$ & $0.16 \pm 0.01$ & $-3.38 \pm 0.78$ \\
\hline SUV-RF & $\begin{array}{l}\text { Small unilamellar vesicles of DSPC, cholesterol, } \\
\text { DSPE-PEG2000-maleimide, and conjugated with RF }\end{array}$ & $147.1 \pm 3.9$ & $0.10 \pm 0.02$ & $-3.42 \pm 0.64$ \\
\hline SUV-G & $\begin{array}{l}\text { Small unilamellar vesicles of DSPC, cholesterol, } \\
\text { DSPE-PEG-NH2, and coated with GSH }\end{array}$ & $102.3 \pm 6.3$ & $0.06 \pm 0.01$ & $-1.70 \pm 0.16$ \\
\hline SUV-T & $\begin{array}{l}\text { Small unilamellar vesicles of DSPC, cholesterol, } \\
\text { DSPE-PEG-NH2, and modified with Tween } 80\end{array}$ & $85.8 \pm 3.7$ & $0.13 \pm 0.03$ & $-3.09 \pm 0.75$ \\
\hline
\end{tabular}

${ }^{a} \mathrm{RF}$, one cell-penetrating peptide; ${ }^{\mathbf{b}} \mathrm{PDI}$, polydispersity index.
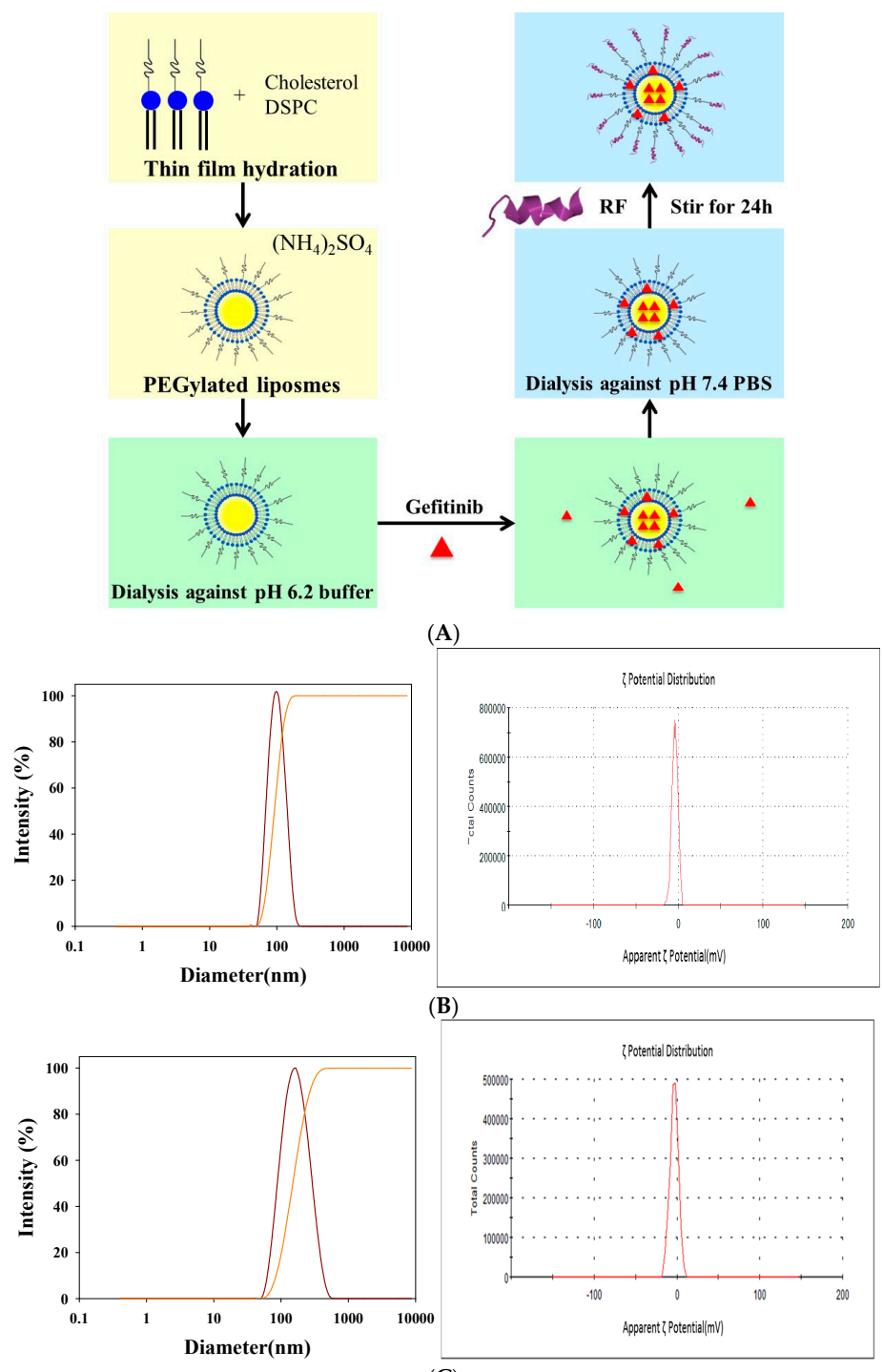

(C)

Figure 1. Cont. 


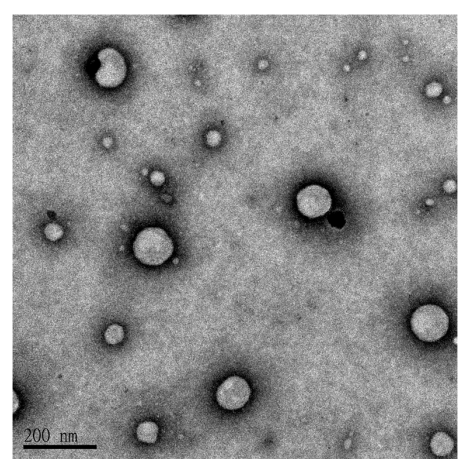

(D)

Figure 1. (A) A schematic diagram for the preparation of PEGylated liposomal delivery system of SUV-Mal and SUV-RF. Particle size distribution and $\zeta$ potential of PEGylated liposomes of: (B) SUV-G+T (SUV-GSH + Tween 80); and (C) SUV-RF. Transmission electron microscopic image of PEGylated liposomes of (D) SUV-RF. Bar $=200 \mathrm{~nm}$.

\subsection{In Vitro Release of Gefitinib from Small Unilamellar Vesicle (SUV)}

The in vitro release experiments of gefitinib alone and gefitinib in SUV-Mal or conjugated with RF were investigated using a dynamic release assay under sink conditions, as shown in Figure 2. The assay was carried out via dialysis using a regenerated cellulose dialysis membrane with an initial gefitinib concentration of $20 \mu \mathrm{M}$, in $500 \mathrm{~mL}$ of phosphate-buffered saline (PBS) with $2 \%$ Tween 80 at $37^{\circ} \mathrm{C}$ for $24 \mathrm{~h}$. We found that a higher release percent from gefitinib alone was monitored in the initial phase compared with the gefitinib release from the SUV-Mal or SUV-RF (Figure 2). It was observed that $86.49 \% \pm 3.54 \%$ of the amount of gefitinib was released after $1 \mathrm{~h}$ when compared with $24.86 \% \pm 1.84 \%$ of gefitinib release for SUV-RF (Figure 2). After $24 \mathrm{~h}$, the amount of gefitinib released from SUV-RF is $84.37 \% \pm 1.97 \%$, in contrast to $97.21 \% \pm 5.65 \%$ of gefitinib being released in its free form (Figure 2).

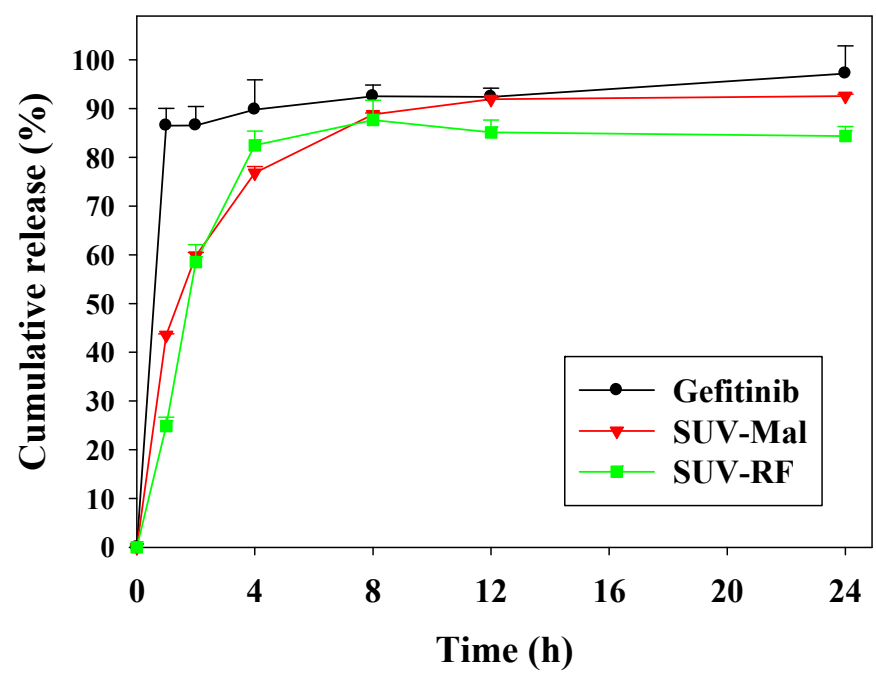

Figure 2. In vitro release of gefitinib from SUV-Mal and SUV-RF. The gefitinib release from liposomes or free drug was conducted in dialysis bag at pH 7.4 PBS with $2 \%$ Tween 80 at $37^{\circ} \mathrm{C}$.

\subsection{The Blood-Brain Barrier (BBB) Barrier Integrity}

The in vitro BBB model was constructed using bEnd.3 cells grown on Transwell inserts of $0.4 \mu \mathrm{m}$ pore size (Figure 3A). Morphology of the BBB model was observed by staining bEnd.3 cells with crystal violet and cell image was captured under a Nikon inverted tissue culture microscope (Figure 3B). The bEnd. 3 cells exhibited dense, uniform, and intact monolayer characteristics. The BBB barrier 
integrity was evaluated by TEER measurement and permeability study (Figure 3C,D). After seeding bEnd.3 cells on inserts for two days, TEER was $91.07 \pm 5.08 \Omega \cdot \mathrm{cm}^{2}$ (Figure 3C). After four-day culture, TEER reached $138.01 \pm 9.70 \Omega \cdot \mathrm{cm}^{2}$, which represented these monolayers were ready for the following experiments as a BBB model (Figure 3C). Consistently, the previous report also used the TEER value above $130 \Omega \cdot \mathrm{cm}^{2}$ for their BBB model [29]. Furthermore, permeability percent of FITC-dextran (molecular weight 70,000 ) across the BBB was $4.02 \% \pm 0.57 \%$ relative to that of FITC-dextran without the BBB (blank) (Figure 3D). According to the previous studies, these researchers also used FITC-dextran (MW 70,000) as a paracellular marker to evaluate the permeability of this marker across the BBB model [30-32]. The BBB barrier integrity was thus verified based on the morphology, TEER, and permeability studies.

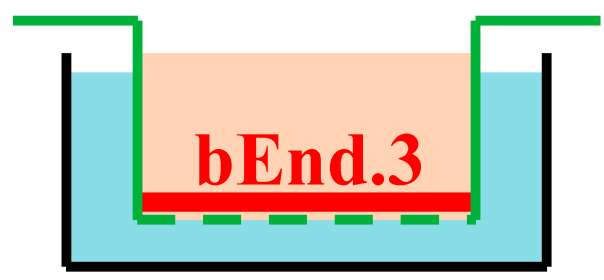

(A)

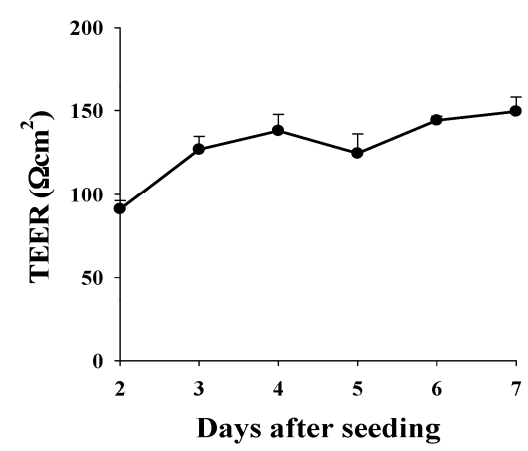

(C)

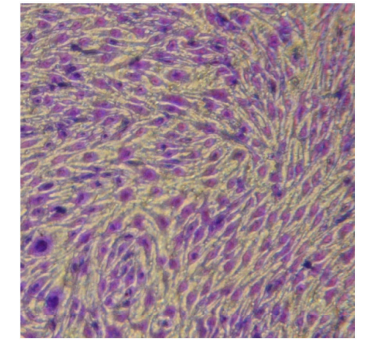

(B)

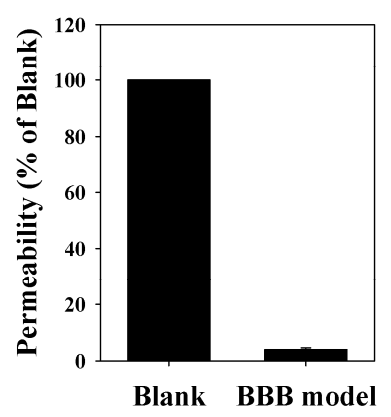

(D)

Figure 3. Establishment and barrier integrity of in vitro blood-brain barrier (BBB) model by growing bEnd.3 monolayer on transwell inserts. (A) Schematic of the in vitro BBB model; (B) Morphology of the BBB model stained with crystal violet. Representative images of intact cell monolayer were captured under a light microscope (magnification, 100×); (C) The TEER values were evaluated for seven days after seeding; (D) Permeability of fluorescein isothiocyanate (FITC)-dextran across the BBB model at Day 7. Values are the mean \pm S.E.M. $(n=3)$.

\subsection{Cytotoxicity of Tween 80, GSH, RF, TAT, and Gefitinib on bEnd.3 and/or PC9 Cells}

We tested the cytotoxicity of Tween 80, GSH, TAT, and RF on bEnd.3 cells by the sulforhodamine B (SRB) assay and found the concentrations of these compounds that maintained the viability of bEnd.3 cells over $90 \%$ (marked as \#) were $400 \mu \mathrm{M}, 0.5 \%, 36$ and $9 \mu \mathrm{M}$, respectively (Figure 4A-D). Interestingly, more than $90 \%$ of bEnd.3 cells kept alive after treatment with gefitinib at $1 \mu \mathrm{M}$ (Figure $4 \mathrm{E}$ ). However, as we increased the concentrations of gefitinib to $10 \mu \mathrm{M}$, viability of bEnd.3 cells was significantly diminished to $60 \%$ (Figure 4E). Furthermore, we evaluated the cytotoxicity of gefitinib on PC9 cells and found that $\mathrm{IC}_{50}$ was $16.34 \mathrm{nM}$ using a regression line for the plot with the linear scale in the $x$-axis (Figure 4 F). Since our purpose was to verify if these liposomal formulations would enhance the cytotoxicity of gefitinib, we determined to use $15 \mathrm{nM}$ of gefitinib for the following investigation. Notably, gefitinib at the concentration of $15 \mathrm{nM}$ did not cause cytotoxicity to bEnd. 3 cells (Figure 4E). 
bEnd3

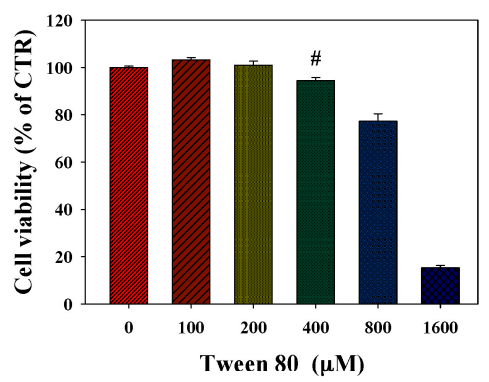

(A)

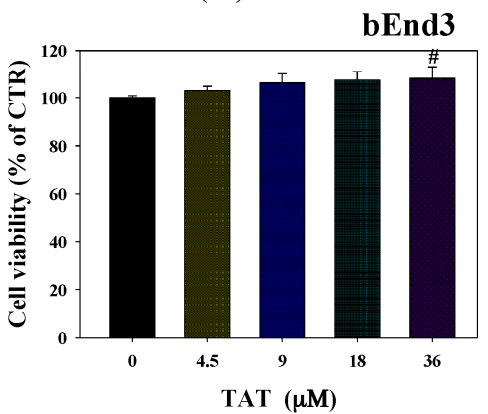

(C)

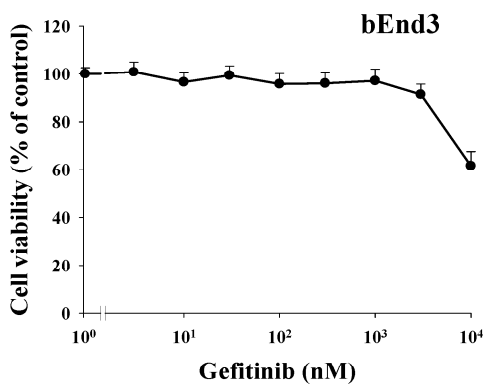

(E)
bEnd3

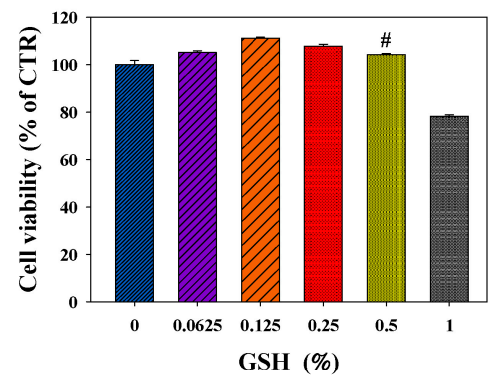

(B)

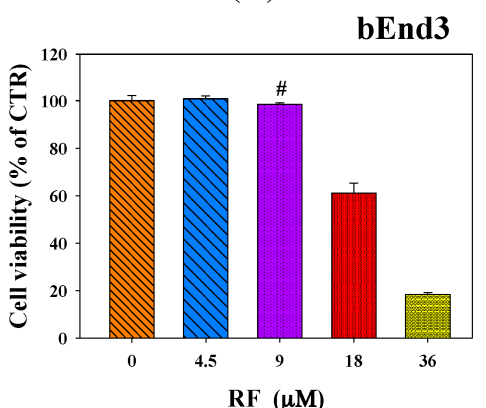

(D)

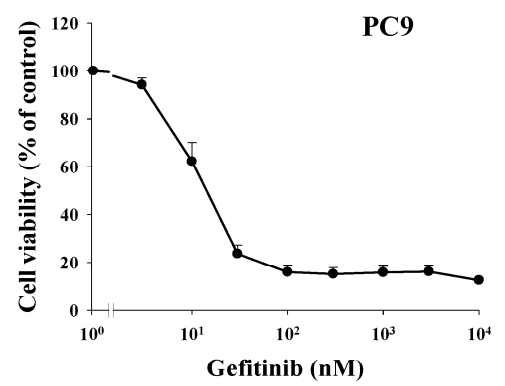

(F)

Figure 4. Cytotoxic effect of gefitinib, Glutathione (GSH), Tween 80, trans-acting activator of transcription (TAT), and RF on PC9 and bEnd.3 cells. bEnd.3 cells were cultured for $24 \mathrm{~h}$ with various concentrations of: (A) Tween 80; (B) GSH; (C) TAT; and (D) RF. Cell viability was determined using SRB assay. (E) bEnd.3 were cultured in various concentrations of gefitinib for $96 \mathrm{~h}$. (F) PC-9 were cultured with various concentrations of gefitinib for $48 \mathrm{~h}$. Cell viability was determined using the sulforhodamine B (SRB) assay. Values are the mean \pm SEM. $(n=3)$. \# represents the non-cytotoxic concentrations of GSH, Tween 80, TAT, and RF, which were used in the following experiments.

\subsection{Cytotoxicity of Gefitinib in SUV-G, SUV-T, SUV-G+T across the BBB on PC9 Cells}

The results showed that the direct cytotoxicity of $15 \mathrm{nM}$ gefitinib on PC9 cells without the BBB (no bEnd.3 cells but with the empty transwell insert) decreased the viability of PC9 cells to $68.81 \% \pm 3.20 \%$ (Figure 5A). The cytotoxic effect of gefitinib across the bEnd.3 cells on PC9 cells was dramatically reduced by existence of the BBB and thus the viability of PC9 cells returned to $90.22 \% \pm 1.95 \%$ (Figure 5A). Gefitinib in the formulations of SUV, SUV-G, and SUV-T did not further improve the cytotoxicity of gefitinib (Figure 5A). However, gefitinib encapsulated in SUV-G+T across the BBB slightly diminished viability of PC9 cells more than that of free gefitinib or SUV (both $p<0.05$; Figure 5A). 


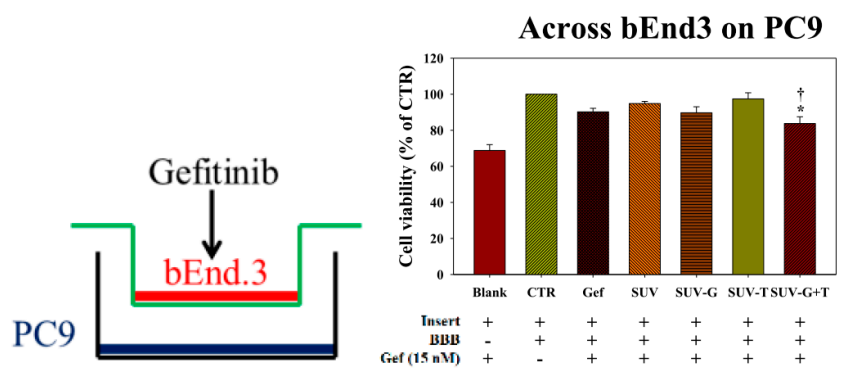

(A)

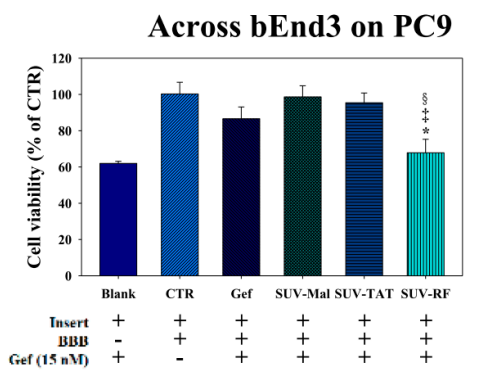

(B)

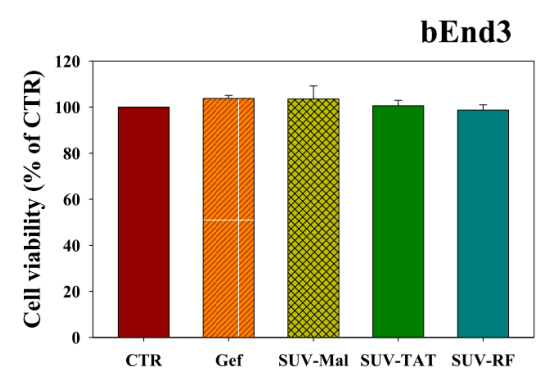

(C)

Figure 5. Cytotoxic effects of different liposomal gefitinib formulations across the BBB on PC9: (A) PC9 cells were treated with free gefitinib, SUV, SUV-G, SUV-T, and SUV-G+T with or without the BBB for 48 h; (B) PC9 were treated with free gefitinib, SUV-Mal, SUV-RF, and SUV-TAT with or without the BBB for $48 \mathrm{~h}$; and (C) bEnd.3 cells were treated with free gefitinib, SUV-Mal, SUV-RF, and SUV-TAT for $48 \mathrm{~h}$. Cell viability was determined using the SRB assay. Values are the mean \pm SEM. $(n=3) .{ }^{*} p<0.05$ compare to the Gef, ${ }^{\dagger} p<0.05$ compare to the SUV, ${ }^{\ddagger} p<0.05$ compare to the SUV-Mal, $\S p<0.05$ compare to the SUV-TAT by Student's $t$-test analysis.

\subsection{Cytotoxicity of Gefitinib in SUV-Mal, SUV-TAT, or SUV-RF across the BBB on PC9 Cells}

Similarly, gefitinib in the formulations of SUV-Mal and SUV-TAT (one well-known cell penetrating peptide) showed no significant difference from cytotoxicity of free gefitinib (both $p>0.05$; Figure 5B). Here, maleimide (Mai) is a linker conjugated on the DSPE-PEG for binding to the SH group of TAT and RF. Nevertheless, SUV-RF (one novel cell penetrating peptide) across the BBB significantly further reduced viability of PC9 cells than that of free gefitinib or SUV-Mal (both $p<0.05$; Figure 5B). Gefitinib in free form or incorporated in SUV-Mal, SUV-TAT, or SUV-RF displayed no cytotoxicity to bEnd.3 cells (Figure 5C) and did not affect the TEER (Figure 6A) of BBB model and permeability of sodium fluorescein across the bEnd.3 monolayer (Figure 6B). 


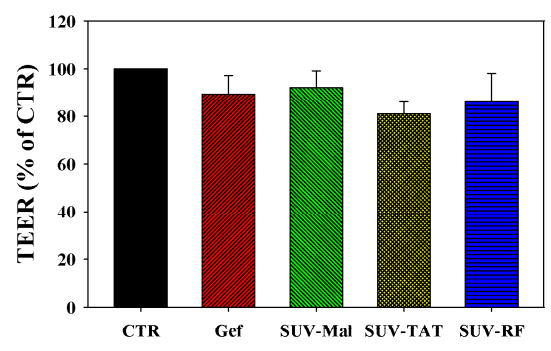

(A)

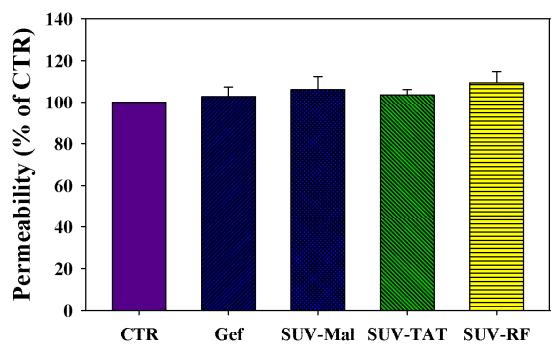

(B)

Figure 6. Effect of SUV-RF on the barrier integrity of the BBB model: (A) transendothelial electrical resistance after 48-h treatment of free gefitinib, SUV-Mal, SUV-RF, and SUV-TAT on bEnd.3 cells; and (B) permeability of sodium fluorescein (SF) across bEnd.3 cells after 48-h treatment of free gefitinib, SUV-Mal, SUV-RF, and SUV-TAT. Values are the mean \pm SEM $(n=4)$.

\subsection{Quantitative Analysis of Cellular Uptake and Transcytosis Mechanisms of SUV-RF}

Because SUV-RF demonstrated the highest cytotoxicity across the BBB on PC9 cells among all the formulations used in this study, we thus chose this formulation for further investigation. The cellular uptake of coumarin-loaded SUV-Mal and SUV-RF by bEnd. 3 cells was monitored by flow cytometer and confocal laser scanning microscope (CLSM), as exhibited in Figure 7. After incubation of cells with SUV-Mal and SUV-RF for $0.5,3$, and $24 \mathrm{~h}$, the mean fluorescence intensity of different treatment groups was normalized relatively to the value of SUV-Mal at $0.5 \mathrm{~h}$. After $3 \mathrm{~h}$ uptake, relative fluorescence intensity of SUV-RF was significantly higher than that of SUV-Mal $(p<0.05$; Figure 7A). As treatment period was increased to $24 \mathrm{~h}$, SUV-RF displayed more intracellular accumulation than that of SUV-Mal $(p<0.01$; Figure 7A). To investigate the mechanism underlying the intracellular uptake of SUVs, various endocytosis inhibitors were pretreated for $30 \mathrm{~min}$ to detect the internalization pattern of SUV-RF. When nystatin, an inhibitor of caveolae-mediated endocytosis was added, the relative uptake percentage was decreased to $85.87 \% \pm 4.63 \%$ for SUV-RF, as demonstrated in Figure $7 \mathrm{~B}$. This indicated that the internalization of SUV-RF was partially mediated via caveolae-mediated transcytosis. Moreover, the pre-treatment of bEnd. 3 cells by poly-lysine for $30 \mathrm{~min}$ before the addition of SUV-RF, an inhibitor of adsorptive transcytosis, the relative uptake percentage was further diminished to $30.91 \% \pm 0.65 \%$ for SUV-RF (Figure 7B). This revealed that the cellular uptake of SUV-RF was mainly mediated through adsorptive transcytosis via electrostatic interaction between cationic RF and anionic membrane surface of bEnd. 3 cells. In contrast, the uptake of SUV-RF had no significant difference before and after addition of 5-(N,N-Dimethyl) amiloride, an inhibitor of micropinocytosis, and chlorpromazine, an inhibitor of clathrin-mediated endocytosis, suggesting no involvement of micropinocytosis and clathrin-mediated endocytosis in the cellular uptake of SUV-RF across the bEnd.3 cells.

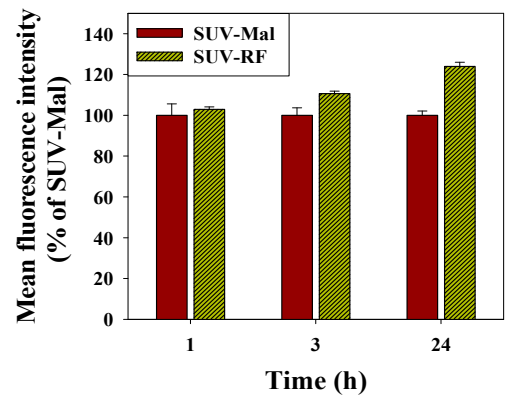

(A)

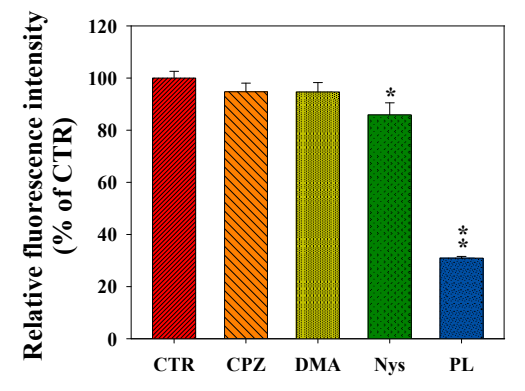

(B)

Figure 7. Cont. 


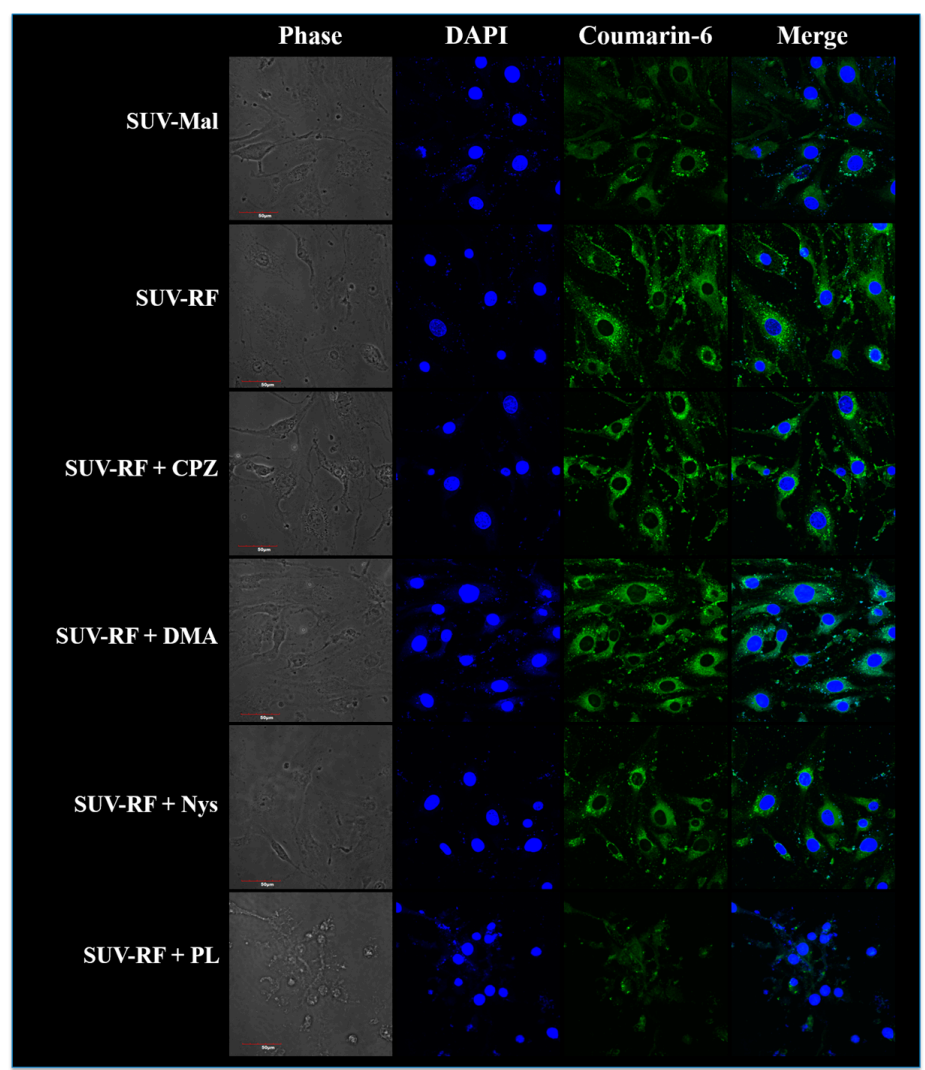

(C)

Figure 7. The cellular uptake mechanisms of SUV-RF. bEnd.3 cells were pre-treated with various endocytosis inhibitors including CPZ $(10 \mu \mathrm{M}$, clathrin-mediated endocytosis inhibitor), DMA $(20 \mu \mathrm{g} / \mathrm{mL}$, macropinocytosis inhibitor), Nys $(10 \mu \mathrm{g} / \mathrm{mL}$, caveolae-mediated endocytosis inhibitor) and PL ( $250 \mu \mathrm{g} / \mathrm{mL}$, positive-charged pathway) for $30 \mathrm{~min}$ and then incubated with coumarin-6-loaded SUV-RF for 90 min. Two methods including: flow cytometry (A,B); and confocal laser scanning microscope $(\mathrm{C})$ were used to detect the relative fluorescence intensity and uptake images of internalized coumarin-6-loaded SUV-RF after treatment of different endocytosis inhibitors. Values are the mean \pm SEM. $(n=3) .{ }^{*} p<0.05,{ }^{* *} p<0.01$ compared to control by Student's $t$-test analysis. Abbreviations: CPZ, chlopromazine hydrochloride; DMA, 5-(N,N-Dimethyl) amiloride hydrochloride; Nys, nystatin; PL, poly-lysine. Bar $=50 \mu \mathrm{m}$.

The cellular uptake of coumarin-loaded SUV-Mal and SUV-RF by bEnd.3 cells was also verified by CLSM (Figure 7C). The cell nucleus was stained with 4',6-diamidino-2-phenylindole (DAPI) (blue) for comparison. After incubation of cells with SUV-Mal or SUV-RF for $90 \mathrm{~min}$, the green fluorescence, including green spots was concentrated and distributed around the cell nucleus. SUV-RF appeared to display intensely additional green fluorescence when compared to SUV-Mal after uptake of these two SUV for $90 \mathrm{~min}$, separately (Figure 7C). The pretreatment of poly-lysine and nystatin inhibited the internalization of SUV-RF onto the bEnd. 3 cells, especially signified by the lower accumulation of SUV-RF around the nucleus by the addition of poly-lysine (Figure 7C). This also supported the uptake mechanisms of SUV-RF via adsorptive- and caveolae-mediated transcytosis provided by the flow cytometric study (Figure 7A,B). 


\section{Discussion}

The major obstacle to treat $\mathrm{BM}$ is the limited penetration of chemotherapy across the blood-brain barrier (BBB). Gefitinib, a first generation EGFR-TKI for treating NSCLC, has low cerebrospinal fluid-to-plasma ratio of about $0.3 \%-1.3 \%$ in patients with BM [3]. This limits the use of gefitinib in treating $\mathrm{BM}$. We thus proposed to establish an in vitro model to mimic the BBB and confirmed the integrity of this BBB monolayer (Figure 3). The nontoxic concentrations of compounds were screened on bEnd.3 cells (Figure 4). We have designed liposomes with two different modifications: SUV-G+T and SUV-RF. The liposomal preparations demonstrated acceptable physicochemical characteristics (Figures 1 and 2, Table 1).

GSH receptors at the BBB interface offer an option in targeting these receptors by GSH-coated nanoparticles to escalate the active or passive transcytosis of therapeutic agents to the brain [12,13]. GSH-PEGylated liposomes have been effectively applied as a brain drug delivery platform for the improvement of numerous treatments. One of the most developed GSH-liposomes is 2B3-101, which is PEGylated liposomal doxorubicin modified with GSH for the treatment of multiple brain cancer indications [15]. We have prepared liposomes with surface coating by GSH in this study. Moreover, liposomes were further modified with Tween 80 to evaluate their BBB penetration ability. Such a design has been found to cross the BBB by augmenting the plasma adsorption of apolipoprotein $\mathrm{E}$ or $\mathrm{B}$ on the nanoparticle surface for increasing binding to the low density lipoproteins (LDL) receptor [18]. Furthermore, nanoparticles modified with Tween 80 may circumvent P-gp transporters, thus intensifying uptake of nanoparticles across the BBB $[19,20]$. In this study, our results mildly supported that gefitinib-encapsulated in liposomes modified with GSH and Tween 80 demonstrated greater cytotoxicity than that of free gefitinib or gefitinib-SUV (both $p<0.05$; Figure 5A). The concentrations of GSH and Tween 80 used in this study were nontoxic to bEnd. 3 cells (Figure 4A,B).

Another approach is to prepare liposomes with surface conjugation to RF for evaluating their BBB penetration effect. RF, a cell-penetrating peptide, possesses 17 amino acid residues and exhibits the structure of $\alpha$-helix. This CPP bears six positive charges and has amphipathic property [27]. It has been reported that cationic $\alpha$-helical CPP, including RF may interact with negatively charged extracellular glycosaminoglycans (GAGs) such as heparan sulfate (HS) via direct translocation and micropinocytosis [33]. The direct translocation is an endocytosis-independent process that the CPPs transport across the cell membrane via the barrel-stave model, inverted micelle model, or carpet model [34,35]. RF bearing Arg and Phe displayed a greater capacity in binding to HS and causing HS-clustering, accounting for a superior cellular uptake ability via electrostatic and hydrophobic interactions when compared with peptides possessing Glu or Ala in HeLa and A549 cells [33]. RF also showed selective cytotoxicity to cancer cells, but exhibited lower cellular uptake into normal cells including mouse fibroblast 3T3-L1 in comparison to TAT [25,33]. Our flow cytometric and CLSM results demonstrated that the endocytosis pathways of the uptake of SUV-RF into bEnd.3 cells was mainly through adsorptive transcytosis-mediated mechanism via electrostatic interaction of positively-charged Arg and Lys in RF with negatively charged glycoproteins of cell membrane and partially through caveolae-mediated transcytosis. Such PEGylated liposomes linked with RF showed efficacy to cross the BBB model to reduce the viability of PC-9 cells and displayed the advantage of low toxicity to bEnd. 3 cells. The proposed schematic illustration of delivery of gefitinib-loaded PEGylated liposomes across the BBB is shown in Figure 8. 


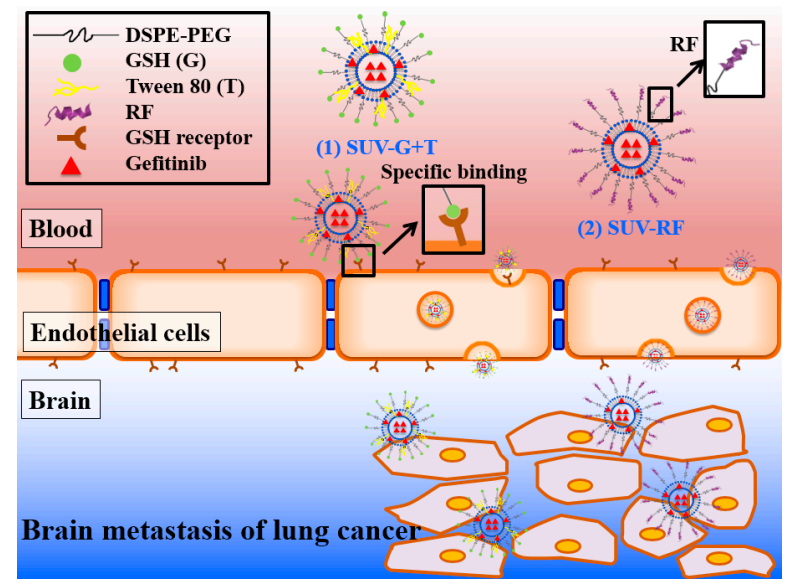

Figure 8. Schematic illustration of delivery of gefitinib-loaded PEGylated liposomes across the BBB. SUV-G+T and SUV-RF may bind to receptors expressed on the surface of brain endothelial cells, enhance gefitinib transport across the BBB, and target to tumor sites.

\section{Materials and Methods}

\subsection{Materials}

Gefitinib was a kind gift or obtained from AstraZeneca, Alderley Park, UK or (AstraZeneca, Macclesfield, Cheshire, UK). RF with the amino acid sequence of GLKKLARLFHKLLKLGC was purchased from Kelowna Biotech (Taipei, Taiwan) at $>95 \%$ purity. Cholesterol was purchased from Sigma-Aldrich (St. Louis, MO, USA). DSPC and DSPE-PEG2000-maleimide were obtained from Avanti Polar Lipids, Inc. (Alabaster, AL, USA). All cell culture medium and reagents were bought from Promega (Madison, WI, USA), Invitrogen (Carlsbad, CA, USA), Gibco BRL (Grand Island, NY, USA), or Hyclone (Logan, UT, USA). All other chemical reagents were obtained from either Merck (Darmstadt, Germany) or Sigma-Aldrich.

\subsection{Preparation of PEGylated Liposomal Gefitinib-Formulations}

DSPC, cholesterol, and DSPE-PEG-NH2 or DSPE-PEG-maleimide (for preparation of SUV-RF) were dissolved in chloroform and methanol (2:1). The resulting lipid solution was then dried using an evaporator. The lipid film was resuspended in $250 \mathrm{mM}$ ammonium sulfate for 20 min under ultrasonication. The dispersion was extruded through a $0.1 \mu \mathrm{m}$ membrane for four times. The product was ultrasonicated for $10 \mathrm{~min}$. Gefitinib was loaded using dialysis against $500 \mathrm{mM}$ sucrose and vortex for $1 \mathrm{~h}$. The final gefitinib-containing liposomes were then dialyzed against $\mathrm{pH}$ 7.4 PBS.

The resultant liposomes were further reacted with RF at molar ratio of DSPE-PEG-maleimide: peptide (TAT or RF) = 1:1.5 for $24 \mathrm{~h}$ at room temperature. To obtain GSH or Tween 80 modification, liposomal solution was mixed with $0.84 \%$ GSH $(w / v \%)$ or $400 \mu \mathrm{M}$ Tween 80 . The mixture was ultrasonicated at room temperature for $30 \mathrm{~min}$ to allow a maximal GSH or Tween 80 modification. After GSH coating, the final liposomes were centrifuged at 15,000 rpm for $5 \mathrm{~min}\left(4^{\circ} \mathrm{C}\right)$ through an Amicon Ultra-4 Centrifuge Filter (10,000 MWCO, Millipore Corp., Bedford, MA, USA). The supernatant was collected and the $\mathrm{pH}$ value was adjusted to 7.4. The above supernatant or GSH standard were then mixed with $6 \mathrm{mM}$ Ellman's reagent (5,5'-dithiobis-2-nitrobenzoic acid (DTNB)). The absorbance of the formed yellow 5-thio-2-nitrobenzoic acid (TNB) proportional to total GSH concentration was measured at $412 \mathrm{~nm}$ at $25{ }^{\circ} \mathrm{C}$ using a Tecan Infinite $200^{\circledR} \mathrm{PRO}$ multimode microplate reader (Männedorf, Switzerland). According to our calculation, the GSH coating percentage was $59.70 \%$. Thus, the final concentration of GSH was determined to be $0.5 \%$ ( $w / v \%)$. Descriptions of these liposomal formulations are demonstrated in Table 1. 
4.3. Characterization of PEGylated Liposomal Gefitinib-Formulations: Encapsulation Efficiency, Size Distribution, Zeta Potential, and Transmission Electron Microscopic Image

Unbound gefitinib was separated from the loaded liposomes by filtration and centrifugation. Gefitinib in the filtrate was analyzed by HPLC. A L7100 chromatography pump (Hitachi, Tokyo, Japan) equipped with an automated injector (Primaide 1210), a 5- $\mu \mathrm{m}$ Luna C18 liquid chromatography (LC) column (Phenomenex, Torrance, CA, USA) and an ultraviolet L2400 detector (Hitachi, Tokyo, Japan) was used for gefitinib analysis. The mobile phase was composed of $0.5 \% \mathrm{KH}_{2} \mathrm{PO}_{4}$, acetonitrile, and methanol $(55: 25: 20, v / v / v)$. The mixture was pre-degassed using a sonicator. The flow rate was $1 \mathrm{~mL} / \mathrm{min}$ at room temperature. The peak area of gefitinib was calculated and compared with the calibration curve for quantitation. Each experiment was performed in quadruplicate.

$\mathrm{EE} \%$ was calculated by the Equation (1) as shown below.

$$
E E \%=\left(\frac{W_{\mathrm{e}}-W_{\mathrm{f}}}{W_{\mathrm{e}}}\right) \times 100 \%
$$

where $W_{\mathrm{e}}$ is the weight of added gefitinib and $W_{\mathrm{f}}$ is the weight of gefitinib in the filtrate.

The size distribution and $\zeta$ potential of liposomes were measured using a Zetasizer Nano ZS90 (Malvern Instruments Ltd., Malvern, Worcestershire, UK) at $25{ }^{\circ} \mathrm{C}$ with a scattering angle of $90.0^{\circ}$. Data was calculated by a cumulant method with Zetasizer family software v7.11 to obtain polydispersity index. Records were analyzed from four individual measurements.

The shape and particle morphology of SUV was observed under TEM. One drop of the sample solution was mounted onto a carbon-coated copper grid (300 mesh) for one minute at room temperature. The grid was air-dried at room temperature for five minutes. One drop of $1 \%$ phosphotungstic acid was then dripped onto the grid for five minutes. The preparation was air-dried for $30 \mathrm{~min}$ and then observed using a JEM 2000EX II transmission electron microscope (JEOL, Ltd., Tokyo, Japan) at $100 \mathrm{kV}$.

\subsection{In Vitro Release of Gefitinib from SUV}

Gefitinib release from SUV was measured using a dynamic release assay under sink conditions. An aliquot of each gefitinib formulation $(1 \mathrm{~mL})$ was put inside a dialysis bag and firmly wrapped. Then the dialysis bags were immersed in $500 \mathrm{~mL}$ of PBS in an incubator at $37^{\circ} \mathrm{C}$ for $24 \mathrm{~h}$ with mild stirring at a rate of $100 \mathrm{rpm}$ for maintaining a uniform drug concentration in the medium. At 1, 2, 4, 8,12 , and $24 \mathrm{~h}$, the samples of $0.1 \mathrm{~mL}$ were removed and stored at $-20^{\circ} \mathrm{C}$ until analysis. With each sampling, the medium was replaced with pre-warmed PBS to maintain the total volume constant. The release of gefitinib from these preparations was sampled up to $24 \mathrm{~h}$. The samples were centrifuged and the concentration of gefitinib in the collected supernatants was detected by HPLC. The cumulative gefitinib released percent was then determined.

\subsection{Culture of Human Lung Adenocarcinoma PC-9 Cells and Murine Brain Endothelial bEnd.3 Cells}

PC-9 cells are a human lung adenocarcinoma cell line harboring a deletion in exon 19 of EGFR [6]. This cell line was provided by Chih-Hsin Yang of National Taiwan University. PC-9 cells were maintained in Roswell Park Memorial Institute-1640 Medium (RPMI-1640; Hyclone) containing $10 \%$ fetal bovine serum (FBS), 1\% L-glutamine (L-G), 1\% penicillin-streptomycin-amphotericin B (PSA) at pH 7.2-7.4. bEnd.3 cells (murine brain endothelial cells) are provided by Prof. Chuen-Mao Yang of Chang Gung University. This cell line was incubated in Dulbecco's Modified Eagle Medium with nutrient mixture F-12 (D-MEM/F12; Gibco) composed of 10\% FBS, 1\% L-glutamine, 1\% PSA, $2.4 \mathrm{~g} / \mathrm{L}$ sodium bicarbonate, and $20 \mathrm{mM}$ HEPES. All the cell culture reagents were purchased from Gibco or HyClone. The culture was maintained at $37^{\circ} \mathrm{C}$ under a humidified atmosphere of $5 \% \mathrm{CO}_{2}$ and $95 \%$ air. 
4.6. Establishment of In Vitro BBB Model: Morphology of Barrier Integrity, Transendothelial Electrical Resistance (TEER) Measurement, and Permeability Measurement

bEnd. 3 cells $\left(5.5 \times 10^{4}\right.$ cell/insert) were seed on 24 -well tissue culture inserts $(0.4 \mu \mathrm{m}$, Transwell, polyester membrane). After culture of different days, the monolayers were evaluated for the following experiments to check the integrity of the BBB model. Morphology of the BBB model was observed by staining bEnd. 3 cells with crystal violet and cell image was captured under a Nikon Diaphot Inverted Tissue Culture Microscope (Diaphot 300, Nikon, Tokyo, Japan).

TEER was measured by a Millicell ERS-2 volt-ohm meter (Millipore Corp.) and a STX01 chopstick-style electrode (Millipore). To calculate TEER $\left(\Omega \cdot \mathrm{cm}^{2}\right)$, electrical resistance across a collagen IV-coated insert without cells $\left(R_{\text {blank }}\right)$ was subtracted from the readings obtained on inserts with cells $\left(R_{\text {total }}\right)$ and this value was multiplied by the surface area $(\mathrm{A})$ of the insert $\left(0.336 \mathrm{~cm}^{2}\right)$. The TEER of the cell monolayers was calculated according to the equation:

$$
\text { TEER }=\left(R_{\text {total }}-R_{\text {blank }}\right) \times \mathrm{A}\left(\Omega \cdot \mathrm{cm}^{2}\right)
$$

where $R_{\text {total }}$ is the resistance measured, $R_{\text {blank }}$ is resistance of control filters without cells and $\mathrm{A}$ is the surface area of filter $\left(0.336 \mathrm{~cm}^{2}\right)$.

After incubation, the upper wells with $100 \mu \mathrm{L}$ of fresh serum-free medium containing $10 \mu \mathrm{g} / \mathrm{mL}$ of sodium fluorescein (376 Da; paracellular marker) or $0.09 \mathrm{mg} / \mathrm{mL}$ of fluorescein isothiocyanate-conjugated dextran (70 KDa FITC-dextran; paracellular marker) were inserted into new lower wells containing $0.6 \mathrm{~mL}$ of fresh serum-free medium. After incubation in the dark at $37^{\circ} \mathrm{C}$ for $1 \mathrm{~h}, 50 \mu \mathrm{L}$ of the lower well media was sampled, and fluorescence intensity of sodium fluorescein or FITC-dextran was measured with excitation at 460 and $494 \mathrm{~nm}$ and emission at 515 and $521 \mathrm{~nm}$, respectively, using a Tecan microplate reader. The relative permeability changes were calculated corresponding to coated inserts without cells, which represented a reference for maximal permeability [36].

$$
\text { Permeability }(\% \text { of max })=\frac{\text { fluorescence intensity } \text { coated inserts with cells }- \text { fluorescence intensity }_{\text {medium }}}{\text { fluorescence intensity }_{\text {inserts }} \text { without cells }}-\text { fluorescence intensity }_{\text {medium }}
$$

\subsection{Cell Viability by the SRB Assay}

After overnight seeding of PC-9 and bEnd.3 cells in 96-well flat-bottomed plates at density of $4 \times 10^{3}$ cells/well and $8 \times 10^{3}$ cells/well, different concentrations of gefitinib were added in the culture medium for the indicated time. The cytotoxic effects were determined by sulforhodamine $B$ assay [37]. Cell viability was determined by dividing the absorbance values of treated cells to that of cells of medium control.

\subsection{Endocytic Uptake Mechanisms of SUV-RF}

bEnd. 3 cells were pre-treated with various endocytosis inhibitors, such as chlopromazine hydrochloride (CPZ; $10 \mu \mathrm{M}$, clathrin-mediated endocytosis inhibitor), 5-( $N, N$-dimethyl) amiloride hydrochloride (DMA; $20 \mu \mathrm{g} / \mathrm{mL}$, micropinocytosis inhibitor), nystatin (Nys; $10 \mu \mathrm{g} / \mathrm{mL}$, caveolae-mediated endocytosis inhibitor) and poly-lysine (PL; $250 \mu \mathrm{g} / \mathrm{mL}$, inhibitor of adsorptive transcytosis) for $30 \mathrm{~min}$ and then incubated with coumarin-6-loaded SUV-RF for $90 \mathrm{~min}$ [38]. Two methods including flow cytometry and confocal laser scanning microscope (CLSM) were used to detect the relative fluorescence intensity and uptake images of internalized coumarin-6-loaded SUV-RF after treatment of different transcytosis inhibitors. For flow cytometric analysis, after incubation of cells with SUV-Mal and SUV-RF for 0.5, 3, and $24 \mathrm{~h}$, the cells were detached by Accumax, collected, and suspended in PBS at $37^{\circ} \mathrm{C}$. Flow cytometric analysis was then carried out using a FACSCalibur flow cytometer (BD Biosciences, San Jose, CA, USA) equipped with an argon ion laser and operated at $488 \mathrm{~nm}$. Fluorescence was measured through a $520 \mathrm{~nm}$ FL1 filter (515-545 nm) for coumarin-6 and fluorescence signals were collected on a logarithmic scale. Data acquisition and analysis were 
performed using commercial BD FACStation ${ }^{\mathrm{TM}}$ software (BD Biosciences). At least 10,000 cells were analyzed in each sample. Within each experiment, determinations were performed in triplicate.

\subsection{Intracellular Uptake of SUV-RF by Confocal Laser Scanning Microscope (CLSM)}

After treatment with various transcytosis inhibitors for $30 \mathrm{~min}$, the cells were further incubated with coumarin-6 (in green)-loaded SUV-RF at $37^{\circ} \mathrm{C}$ for $90 \mathrm{~min}$. The cells were then rinsed using PBS. The images were taken using a confocal laser-scanning microscope (Olympus FV10i, Olympus America Inc., Center Valley, PA, USA) with excitation at $490 \mathrm{~nm}$ and emission at $520 \mathrm{~nm}$. The cells were also stained with DAPI (in blue) in the nucleus for comparison. At least 3 photos were taken in each sample. The representative image of each treatment is exhibited.

\subsection{Statistical Analysis}

Experimental data were analyzed by Student's $t$-test and expressed as the mean \pm SEM. Statistical significance was set at $p<0.05$.

\section{Conclusions}

Taken together, cell selective CPP-conjugated SUV-RF shed light on improving gefitinib delivery across the BBB via modulating the transcytosis pathway(s). We expect that gefitinib loaded SUV-RF will potentially become a more promising brain delivery platform due to their ability to increase penetration across the BBB and enhance targeting to the tumor cells. This liposomal formulation may reduce the off-target side effects to normal brain cells. The special and serious situation of brain metastases highlights the necessity for a multifunctional approach integrating an effective delivery system to carry gefitinib as a potential nanomedicine to enhance the clinical efficacy of target therapy.

Acknowledgments: This work was financially supported by grants from Ministry of Science and Technology of Taiwan (MOST 104-2320-B-010-004-MY2), Veterans General Hospitals and University System of Taiwan (VGHUST105-G7-8-3), Veterans General Hospitals (V105C-031), Ministry of Education, Aiming for the Top University Plan, and National Yang-Ming University (103AC-D112). We thank Chih-Hsin Yang of National Taiwan University for supplying gefitinib and PC9 used in this study. We thank Chuen-Mao Yang of Chang-Gung University for providing the bEnd.3 cells.

Author Contributions: Kuan-Hung Lin and Shu-Ting Hong performed the experiments and analyzed the data; Yu-Li Lo conceived, designed and interpreted the experiments as well as wrote the manuscript; Anya Maan-Yuh Lin conceived and interpreted the experiments; Chih-Hsin James Yang and Hsiang-Tsui Wang interpreted the experiments; and Yu-Li Lo, Anya Maan-Yuh Lin and Chih-Hsin James Yang contributed reagents/materials/analysis tools. All authors approved the final version of the manuscript.

Conflicts of Interest: The authors declare no conflict of interest.

\section{References}

1. Tang, M.-C.; Wu, M.-Y.; Hwang, M.-H.; Chang, Y.-T.; Huang, H.-J.; Lin, A.M.-Y.; Yang, J.C.-H. Chloroquine enhances gefitinib cytotoxicity in gefitinib-resistant nonsmall cell lung cancer cells. PLoS ONE 2015, 10, e0119135. [CrossRef] [PubMed]

2. Fidler, I.J. The biology of brain metastasis: Challenges for therapy. Cancer J. 2015, 21, 284-293. [CrossRef] [PubMed]

3. Zeng, Y.D.; Liao, H.; Qin, T.; Zhang, L.; Wei, W.D.; Liang, J.Z.; Xu, F.; Dinglin, X.X.; Ma, S.X.; Chen, L.K. Blood-brain barrier permeability of gefitinib in patients with brain metastases from non-small-cell lung cancer before and during whole brain radiation therapy. Oncotarget 2015, 6, 8366-8376. [CrossRef] [PubMed]

4. Chen, Y.; Liu, L. Modern methods for delivery of drugs across the blood-brain barrier. Adv. Drug Deliv. Rev. 2012, 64, 640-665. [CrossRef] [PubMed]

5. On, N.H.; Miller, D.W. Transporter-based delivery of anticancer drugs to the brain: Improving brain penetration by minimizing drug efflux at the blood-brain barrier. Curr. Pharm. Des. 2014, 20, 1499-1509. [CrossRef] [PubMed] 
6. Huang, M.H.; Lee, J.H.; Chang, Y.J.; Tsai, H.H.; Lin, Y.L.; Lin, A.M.; Yang, J.C. MEK inhibitors reverse resistance in epidermal growth factor receptor mutation lung cancer cells with acquired resistance to gefitinib. Mol. Oncol. 2013, 7, 112-120. [CrossRef] [PubMed]

7. Zhang, J.; Yu, J.; Sun, X.; Meng, X. Epidermal growth factor receptor tyrosine kinase inhibitors in the treatment of central nerve system metastases from non-small cell lung cancer. Cancer Lett. 2014, 351, 6-12. [CrossRef] [PubMed]

8. Jamal-Hanjani, M.; Spicer, J. Epidermal growth factor receptor tyrosine kinase inhibitors in the treatment of epidermal growth factor receptor-mutant non-small cell lung cancer metastatic to the brain. Clin. Cancer Res. 2012, 18, 938-944. [CrossRef] [PubMed]

9. Haringhuizen, A.; van Tinteren, H.; Vaessen, H.F.; Baas, P.; van Zandwijk, N. Gefitinib as a last treatment option for non-small-cell lung cancer: Durable disease control in a subset of patients. Ann. Oncol. 2004, 15, 786-792. [CrossRef] [PubMed]

10. Dorr, R.T. Pharmacology and toxicology of Cremophor EL diluent. Ann. Pharmacother. 1994, 28, S11-S14. [PubMed]

11. Masserini, M. Nanoparticles for brain drug delivery. ISRN Biochem. 2013, 2013, 238428. [CrossRef] [PubMed]

12. Grover, A.; Hirani, A.; Pathak, Y.; Sutariya, V. Brain-targeted delivery of docetaxel by glutathione-coated nanoparticles for brain cancer. AAPS PharmSciTech 2014, 15, 1562-1568. [CrossRef] [PubMed]

13. Geldenhuys, W.; Wehrung, D.; Groshev, A.; Hirani, A.; Sutariya, V. Brain-targeted delivery of doxorubicin using glutathione-coated nanoparticles for brain cancers. Pharm. Dev. Technol. 2015, 20, 497-506. [CrossRef] [PubMed]

14. Gaillard, P.J.; Appeldoorn, C.C.; Dorland, R.; van Kregten, J.; Manca, F.; Vugts, D.J.; Windhorst, B.; van Dongen, G.A.; de Vries, H.E.; Maussang, D.; et al. Pharmacokinetics, brain delivery, and efficacy in brain tumor-bearing mice of glutathione pegylated liposomal doxorubicin (2B3-101). PLoS ONE 2014, 9, e82331. [CrossRef] [PubMed]

15. Birngruber, T.; Raml, R.; Gladdines, W.; Gatschelhofer, C.; Gander, E.; Ghosh, A.; Kroath, T.; Gaillard, P.J.; Pieber, T.R.; Sinner, F. Enhanced doxorubicin delivery to the brain administered through glutathione PEGylated liposomal doxorubicin (2B3-101) as compared with generic Caelyx ${ }^{\circledR} /$ Doxil $^{\circledR}$ —A cerebral open flow microperfusion pilot study. J. Pharm. Sci. 2014, 103, 1945-1948. [CrossRef] [PubMed]

16. Voigt, N.; Henrich-Noack, P.; Kockentiedt, S.; Hintz, W.; Tomas, J.; Sabel, B.A. Surfactants, not size or zeta-potential influence blood-brain barrier passage of polymeric nanoparticles. Eur. J. Pharm. Biopharm. 2014, 87, 19-29. [CrossRef] [PubMed]

17. Blasi, P.; Schoubben, A.; Traina, G.; Manfroni, G.; Barberini, L.; Alberti, P.F.; Cirotto, C.; Ricci, M. Lipid nanoparticles for brain targeting III. Long-term stability and in vivo toxicity. Int. J. Pharm. 2013, 454, 316-323. [CrossRef] [PubMed]

18. Kolter, M.; Ott, M.; Hauer, C.; Reimold, I.; Fricker, G. Nanotoxicity of poly(N-butylcyano-acrylate) nanoparticles at the blood-brain barrier, in human whole blood and in vivo. J. Control. Release 2015, 197, 165-179. [CrossRef] [PubMed]

19. Jose, S.; Sowmya, S.; Cinu, T.A.; Aleykutty, N.A.; Thomas, S.; Souto, E.B. Surface modified PLGA nanoparticles for brain targeting of Bacoside-A. Eur. J. Pharm. Sci. 2014, 63, 29-35. [CrossRef] [PubMed]

20. Van der Meel, R.; Vehmeijer, L.J.; Kok, R.J.; Storm, G.; van Gaal, E.V. Ligand-targeted particulate nanomedicines undergoing clinical evaluation: Current status. Adv. Drug Deliv. Rev. 2013, 65, 1284-1298. [CrossRef] [PubMed]

21. Bolhassani, A. Potential efficacy of cell-penetrating peptides for nucleic acid and drug delivery in cancer. Biochim. Biophys. Acta 2011, 1816, 232-246. [CrossRef] [PubMed]

22. Zong, T.; Mei, L.; Gao, H.; Cai, W.; Zhu, P.; Shi, K.; Chen, J.; Wang, Y.; Gao, F.; He, Q. Synergistic dual-ligand doxorubicin liposomes improve targeting and therapeutic efficacy of brain glioma in animals. Mol. Pharm. 2014, 11, 2346-2357. [CrossRef] [PubMed]

23. Wen, X.; Wang, K.; Zhao, Z.; Zhang, Y.; Sun, T.; Zhang, F.; Wu, J.; Fu, Y.; Du, Y.; Zhang, L.; et al. Brain-targeted delivery of trans-activating transcriptor-conjugated magnetic PLGA/lipid nanoparticles. PLOS ONE 2014, 9, e106652. [CrossRef] [PubMed]

24. Lim, S.; Kim, W.J.; Kim, Y.H.; Choi, J.M. Identification of a novel cell-penetrating peptide from human phosphatidate phosphatase LPIN3. Mol. Cells 2012, 34, 577-582. [CrossRef] [PubMed] 
25. Park, H.; Tsutsumi, H.; Mihara, H. Cell-selective intracellular drug delivery using doxorubicin and $\alpha$-helical peptides conjugated to gold nanoparticles. Biomaterials 2014, 35, 3480-3487. [CrossRef] [PubMed]

26. Usui, K.; Kakiyama, T.; Tomizaki, K.Y.; Mie, M.; Kobatake, E.; Mihara, H. Cell fingerprint patterns using designed $\alpha$-helical peptides to screen for cell-specific toxicity. Bioorgan. Med. Chem. Lett. 2011, 21, 6281-6284. [CrossRef] [PubMed]

27. Usui, K.; Kikuchi, T.; Mie, M.; Kobatake, E.; Mihara, H. Systematic screening of the cellular uptake of designed $\alpha$-helix peptides. Bioorgan. Med. Chem. 2013, 21, 2560-2567. [CrossRef] [PubMed]

28. Park, H.; Tsutsumi, H.; Mihara, H. Cell penetration and cell-selective drug delivery using $\alpha$-helix peptides conjugated with gold nanoparticles. Biomaterials 2013, 34, 4872-4879. [CrossRef] [PubMed]

29. Brown, R.C.; Morris, A.P.; O'Neil, R.G. Tight junction protein expression and barrier properties of immortalized mouse brain microvessel endothelial cells. Brain Res. 2007, 1130, 17-30. [CrossRef] [PubMed]

30. Weksler, B.B.; Subileau, E.A.; Perriere, N.; Charneau, P.; Holloway, K.; Leveque, M.; Tricoire-Leignel, H.; Nicotra, A.; Bourdoulous, S.; Turowski, P.; et al. Blood-brain barrier-specific properties of a human adult brain endothelial cell line. FASEB J. 2005, 19, 1872-1874. [CrossRef] [PubMed]

31. Liu, J.; Jin, X.; Liu, K.J.; Liu, W. Matrix metalloproteinase-2-mediated occludin degradation and caveolin-1-mediated claudin-5 redistribution contribute to blood-brain barrier damage in early ischemic stroke stage. J. Neurosci. 2012, 32, 3044-3057. [CrossRef] [PubMed]

32. Li, G.; Simon, M.J.; Cancel, L.M.; Shi, Z.D.; Ji, X.; Tarbell, J.M.; Morrison, B., 3rd; Fu, B.M. Permeability of endothelial and astrocyte cocultures: In vitro blood-brain barrier models for drug delivery studies. Ann. Biomed. Eng. 2010, 38, 2499-2511. [CrossRef] [PubMed]

33. Yang, J.; Tsutsumi, H.; Furuta, T.; Sakurai, M.; Mihara, H. Interaction of amphiphilic $\alpha$-helical cell-penetrating peptides with heparan sulfate. Org. Biomol. Chem. 2014, 12, 4673-4681. [CrossRef] [PubMed]

34. Trabulo, S.; Mano, M.; Faneca, H.; Cardoso, A.L.; Duarte, S.; Henriques, A.; Paiva, A.; Gomes, P.; Simoes, S.; de Lima, M.C. S4 $13-\mathrm{PV}$ cell penetrating peptide and cationic liposomes act synergistically to mediate intracellular delivery of plasmid DNA. J. Gene Med. 2008, 10, 1210-1222. [CrossRef] [PubMed]

35. Trabulo, S.; Cardoso, A.L.; Cardoso, A.M.; Morais, C.M.; Jurado, A.S.; Pedroso de Lima, M.C. Cell-penetrating peptides as nucleic acid delivery systems: From biophysics to biological applications. Curr. Pharm. Des. 2013, 19, 2895-2923. [CrossRef] [PubMed]

36. Niego, B.; Freeman, R.; Puschmann, T.B.; Turnley, A.M.; Medcalf, R.L. t-PA-specific modulation of a human blood-brain barrier model involves plasmin-mediated activation of the Rho kinase pathway in astrocytes. Blood 2012, 119, 4752-4761. [CrossRef] [PubMed]

37. Vichai, V.; Kirtikara, K. Sulforhodamine B colorimetric assay for cytotoxicity screening. Nat. Protoc. 2006, 1, 1112-1116. [CrossRef] [PubMed]

38. Yumoto, R.; Suzuka, S.; Oda, K.; Nagai, J.; Takano, M. Endocytic uptake of FITC-albumin by human alveolar epithelial cell line A549. Drug Metab. Pharmacokinet. 2012, 27, 336-343. [CrossRef] [PubMed]

(C) 2016 by the authors; licensee MDPI, Basel, Switzerland. This article is an open access article distributed under the terms and conditions of the Creative Commons Attribution (CC-BY) license (http://creativecommons.org/licenses/by/4.0/). 